\title{
Microwave assisted synthesis, antibacterial activity against Bordetella bronchiseptica of a library of 3 '-hydroxyaryl and heteroaryl chalcones and molecular descriptors-based SAR
}

\author{
Farzana Latif Ansari*a ${ }^{\text {, }}$ Muhammad Baseer ${ }^{\mathrm{a}}$, Fatima Iftikhar ${ }^{\mathrm{a}}$, Saima Kulsoom ${ }^{\mathrm{a}}$, \\ Ahsan Ullah ${ }^{a}$, Samina Nazir ${ }^{a}$, Awais Shaukat ${ }^{a}$, Ihsan-ul-Haq, ${ }^{b}$ and Bushra Mirza ${ }^{b}$ \\ ${ }^{a}$ Department of Chemistry, Quaid-i-Azam University, Islamabad, Pakistan \\ ${ }^{b}$ Department of Biochemistry, Quaid-i-Azam University, Islamabad, Pakistan \\ P.O. Box 45320 \\ E-mail:flaqau@yahoo.com
}

\begin{abstract}
Microwave assisted synthesis of 33 membered parallel library of aryl- and heteroaryl chalcones was carried out by reaction of 3-hydroxyacetophenone with different substituted aryl- and heteroaryl aldehydes under Claisen-Schmidt conditions. The synthesized chalcones are significantly active against Bordetella bronchiseptica (ATCC 4617), gram negative respiratory pathogen that infects wide range of animals and human using cefixime as standard antibiotic as control. Tested compounds show moderate inhibitory activities (zone of inhibition 18.5-10.5 $\mathrm{mm}$ ) compared to standard (zone of inhibition 13.0). All halogen substituted chalcones are most active members of the library while nitrochalcones and nitrogen containing heteroarylchalcones are least potent and 3-bromochalcone (16) was identified as lead structure of the library. Quantitative structure activity relationship was established to find dependency trend in sterms of bactericidal activity with number of molecular descriptors and some suggestive correlations of activity with these descriptors. Quantitative structure activity relationship was established using MOE software package showing good correlation of activity with various physicochemical parameters e.g. Hammett substituent constant $\sigma, E_{\mathrm{HOMO}}, \log P$ and molar volume $V m$. It was observed that bactericidal potency of chalcones was dependent more on steric than on electronic descriptors. Chalcones with electron acceptors on phenyl ring and those with greater lipophilic character were expected to be stronger inhibitors of B. bronchiseptica with exception of nitrosubstituted chalcones. This study, therefore, facilitate design and synthesis of chalcones with higher potency to serve as potential inhibitors of B. bronchiseptica, thereby, helping to establish breakpoints for antimicrobial agents for which no systematic study is currently available.
\end{abstract}

Keywords: Bordetella bronchiseptic, chalcones, microwave assisted synthesis, molecular descriptors, SAR 


\section{Introduction}

Bordetella bronchiseptica ATCC 4617 is an aerobic, gram-negative bacterium that belongs to the genus Bordetella within the family Alcaligenaceae. ${ }^{1}$ It causes respiratory tract infections in a wide variety of domestic and wild animals particularly in dogs, swine, rabbits and pigs leading to a number of respiratory tract diseases such as atrophic rhinitis. Although B. bronchiseptica is considered as a zoonotic agent, it causes respiratory infections in humans too. Most frequently, B. bronchiseptica infections in humans are seen in immunocompromised individuals with increasing number of cases in AIDS patients or in elderly people. ${ }^{2}$ During infection, it produces adhesions which help the bacteria to adhere to ciliated cells causing mechanical blocking of the respiratory cilia, resulting in failure of the respiratory tract to clear mucus secretions. ${ }^{3}$ For the treatment and control of respiratory tract infections some antimicrobial agents such as trimethoprim, sulfonamides, tetracycline and $\beta$-lactams are used most frequently. However, the current vaccines and therapies are not capable of eliminating infections as relapses have been commonly observed and a long duration of antibiotic therapy is generally required. ${ }^{4,5}$

Compounds with a chalcone-based structure show an array of pharmacological activities e.g. anti-inflammatory, ${ }^{6}$ antioxidant, ${ }^{7}$ antiviral, ${ }^{8}$ antibacterial, ${ }^{9,10}$ antileishmanial, ${ }^{11} \mathrm{~K}^{+}$channel inhibitor, ${ }^{12}$ and as antituberculotics, ${ }^{13}$ are only some of the properties that are widely cited. Although a number of reports have focused on the synthesis and antibacterial properties of chalcones, ${ }^{14-17}$ however, their potential as antibacterial agents against B. bronchiseptica has not yet been explored. We have reported earlier the design and synthesis of a 120-member library and its screening against a number of bacterial strains and the lead structure was identified through deconvolution based on positional scanning protocol. ${ }^{18}$ Prompted by the findings and in continuation to our interest in the synthesis of biodynamic chalcones, ${ }^{19,20}$ we synthesized a parallel library of 3-hydroxy-aryl and heteroaryl chalcones in order to study their bactericidal potential against $B$. bronchiseptica. Although we tested these compounds also against a number of other gram-positive and gram-negative bacterial strain namely, Micrococcus leuteus ATCC10240, Pseudomonas picketti ATCC 49129, Escherichia coli ATCC 15224, Enterobacter aerogenes ATCC 13048, and Salmonella setubal ATCC 19196, however, with the exception of $B$. bronchiseptica all the compounds were found to be generally inactive against these strains.

Although chalcones are an-easy-to synthesize template but a great diversity of the methods is available in literature that describe their synthesis under acid or base catalysis ${ }^{21}$ making use of conventional thermal energy and microwave irradiation ${ }^{22,23}$ or under sonocatalytic conditions. $^{24,25}$ We present, herein, the Claisen-Schmidt synthesis of two sets of 3hydroxychalcones by the reaction of 3-hydroxyacetophenone with different substituted aryl- and heteroarylaldehydes. The synthesis has been conducted under microwave irradiation to circumvent the problem of increasing community concern over possible influence of chemicals and chemical processes on the environment. ${ }^{26}$

Agar well-diffusion method ${ }^{18}$ was used for the study of the potential of these compounds against $B$. bronchiseptica as this bacterium can be grown easily in vitro on agar and broth 
medium, thereby making it possible to use this method to detect its susceptibility against any drug. A quantitative structure activity relationship has been interpreted by calculating a number of electronic parameters by the use of software package Molecular Operating Environment (MOE) ${ }^{27}$ and very good SAR was established with a number of physicochemical determinants especially with $E_{\mathrm{HOMO}}$ and $\log P$.

\section{Results and Discussion}

\section{Synthesis}

Microwave enhanced synthesis of chalcones 1-23 of Set 1 and 24-33 of Set 2 was carried out under Claisen Schmidt conditions using different substituted aryl- and heteroarylaldehydes respectively as shown in Scheme 1.

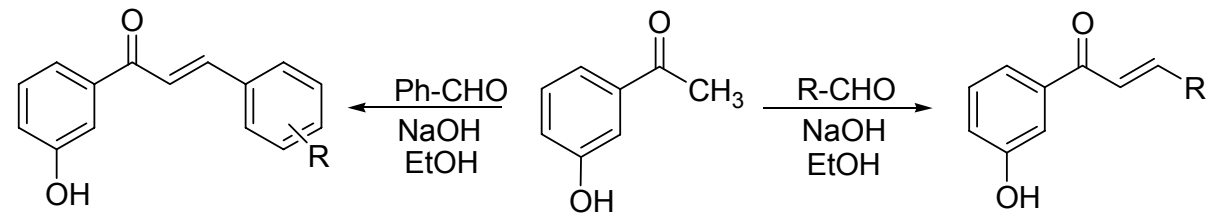

Set 1

\begin{tabular}{|c|c|}
\hline $\mathbf{R}$ & $\mathbf{R}$ \\
\hline 1. $\mathrm{H}$ & 13. $2-\mathrm{Cl}$ \\
\hline 2.2-OH & $14.3-\mathrm{Cl}$ \\
\hline 3. $3-\mathrm{OH}$ & 15.4-Cl \\
\hline 4. $4-\mathrm{OH}$ & $16.3-\mathrm{Br}$ \\
\hline 5.2-OMe & 17.4-Br \\
\hline 6.3-OMe & $18.2-\mathrm{NO}_{2}$ \\
\hline 7.4-OMe & 19. $3-\mathrm{NO}_{2}$ \\
\hline 8. $3,4-\mathrm{OMe}_{2}$ & 20. $4-\mathrm{NO}_{2}$ \\
\hline 9.4-OH,3-OMe & 21.4- $-\mathrm{NMe}_{2}$ \\
\hline $10.2-\mathrm{F}$ & 22.4-Me \\
\hline 11.3-F & 23. $2-\mathrm{Me}-3,5-\mathrm{OMe}$ \\
\hline $12.4-\mathrm{F}$ & \\
\hline
\end{tabular}

Set 2

$\mathbf{R}$

24. Pyridin-2-yl

25. Pyridin-3-yl

26. Pyridin-4-yl

27.Pyrrol-2-yl

28. Furan-2-yl

29.Indol-3-yl

30.Thien-2-yl

31. Thien-2-yl,5-Me

32. Thien-2-yl,5-Br

33. Thien-2-yl,5- $\mathrm{NO}_{2}$

Scheme 1. Synthesis of chalcones of Set 1 (1-23) and Set 2 (24-33).

The selection of the substituents on the phenyl ring of the chalcones of Set 1 was made on the basis of their size, lipophilicity and electronic properties and they were changed systematically once at a time at 2-3- and 4-positions to get a set of regioisomers. The chalcones of Set 2 varied with respect to the attachment of the heterocyclic ring to the propenone unit of chalcone. The reaction time under microwave irradiation varied from 30 to $180 \mathrm{sec}$. However, chalcones 2-4, 9 and all heteroaryl chalcones (24-33) were synthesized by conventional 
method $^{19)}$ as the reaction mixture decomposed on irradiation. The yield varied from 49 to $93 \%$, however, the yield of chalcones 2-4, 6, 22, 26, 28-29 and 33 was found to be low. All compounds were characterized on the basis of their physicochemical constants, and their mass and ${ }^{1} \mathrm{H}-\mathrm{NMR}$ spectral data.

\section{In vitro antibacterial screening}

The members of the parallel library of 3-hydroxychalcones were tested for their in vitro bactericidal action against six bacterial strains i.e. B. bronchiseptica, M. leuteus, P. picketti, E. coli, E. aerogenes and S. setubal following agar well-diffusion method ${ }^{18)}$ using cefixime as standard drug. Interestingly, all the tested chalcones showed significant potential as bactericidals only against $B$. bronchiseptica with a zone of inhibition varying from $9.5-18.5 \mathrm{~mm}$ in diameter compared to cefixime (with $31 \& 34 \mathrm{~mm}$ zone of inhibition respectively). These results along with the MIC values are shown in Table 1 while a graphical representation of the same data is given in Figure 1.

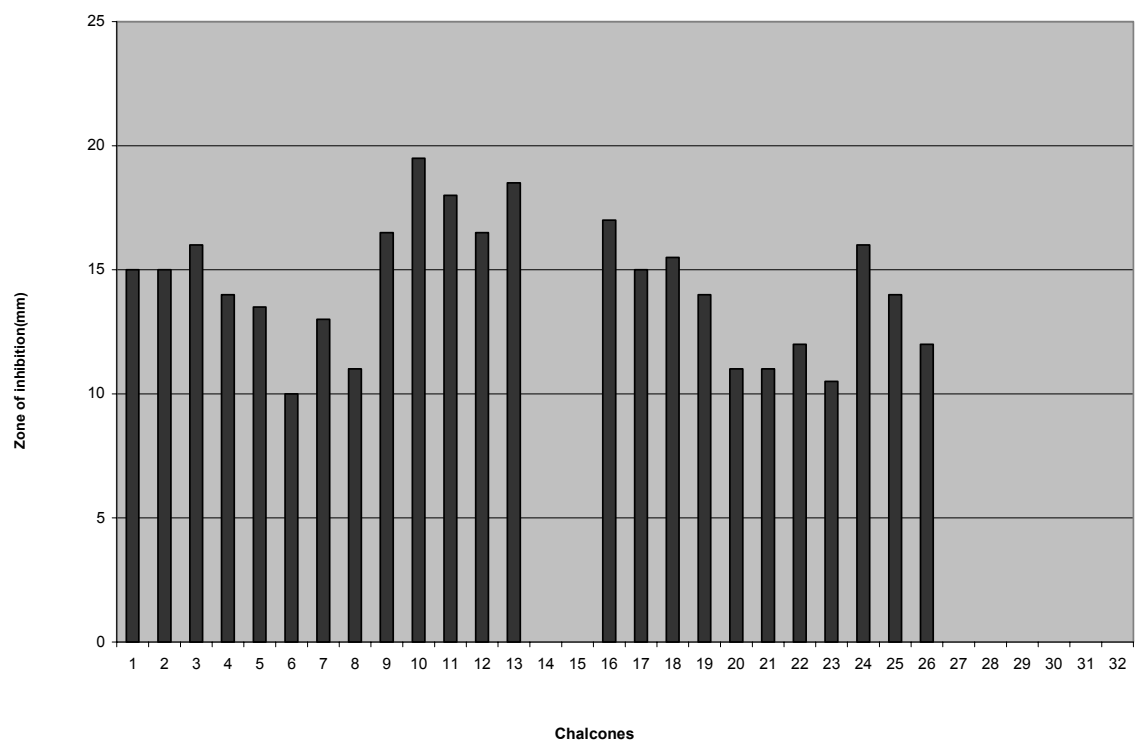

Figure 1. Graphical representation of in vitro antibacterial activities of 3'-hydroxy chalcones.

The results of antibacterial activity of chalcones against $B$. bronchiseptica are shown in Table 1 as zone of inhibition (in $\mathrm{mm}$ ) and minimum inhibitory concentration, MIC (mg/ml). The chalcones having the lipophilic bromo- and chloro- groups $(14 \& \mathbf{1 6})$ showed the greatest antibacterial activity (zone of inhibition $18.5 \mathrm{~mm}$ with MIC 0.3 and $0.2 \mathrm{mg} / \mathrm{ml}$ ) respectively, whereas chalcones with the more polar and electron withdrawing nitro groups $(\mathbf{1 8}, 19$ and 20) were least active. The chalcones with the polar hydroxyl- and methoxy- groups were found to be intermediate in activity. The following trend of the bactericidal activity was observed in chalcones of Set 1.

$$
\begin{gathered}
\mathrm{X}>\mathrm{OH}>\mathrm{OMe}>\mathrm{NO}_{2} \\
\text { where } \mathrm{X}=\mathrm{F}, \mathrm{Cl}, \mathrm{Br}
\end{gathered}
$$


Table 1. In vitro antibacterial activities of $3^{`}$-hydroxychalcones against $B$. bronchiseptica

\begin{tabular}{|c|c|c|c|c|}
\hline & No. & $\mathrm{R}$ & $\begin{array}{c}\text { Zone of } \\
\text { Inhibition }(\mathrm{mm})\end{array}$ & $\begin{array}{c}\mathrm{MIC} \\
(\mathrm{mg} / \mathrm{ml})\end{array}$ \\
\hline \multirow{23}{*}{ "ָ } & 1 & $\mathrm{Ph}$ & 15.0 & 0.5 \\
\hline & 2 & 2-OHPh & 15.0 & 0.7 \\
\hline & 3 & 3-OHPh & 12.0 & 0.7 \\
\hline & 4 & 4-OHPh & 14.0 & 0.8 \\
\hline & 5 & 2-OMePh & 13.0 & 0.5 \\
\hline & 6 & 3-OMePh & 10.0 & 1.0 \\
\hline & 7 & 4-OMePh & 13.0 & 0.6 \\
\hline & 8 & $3,4-\mathrm{OMe}_{2} \mathrm{Ph}$ & 11.0 & - \\
\hline & 9 & 3-OH,4-OMePh & Nil & - \\
\hline & 10 & 2-FPh & - & - \\
\hline & 11 & $3-\mathrm{FPh}$ & - & - \\
\hline & 12 & 4-FPh & 16.0 & 0.4 \\
\hline & 13 & 2-ClPh & 16.0 & 0.5 \\
\hline & 14 & 3-ClPh & 18.0 & 0.3 \\
\hline & 15 & 4-ClPh & 18.0 & 0.2 \\
\hline & 16 & 3-BrPh & 18.5 & 0.2 \\
\hline & 17 & 4-BrPh & - & - \\
\hline & 18 & $2-\mathrm{NO}_{2} \mathrm{Ph}$ & 9.0 & 1.0 \\
\hline & 19 & $3-\mathrm{NO}_{2} \mathrm{Ph}$ & 10.5 & 0.8 \\
\hline & 20 & $4-\mathrm{NO}_{2} \mathrm{Ph}$ & 10.5 & 1.0 \\
\hline & 21 & $4-\mathrm{NMe}_{2} \mathrm{Ph}$ & 0 & - \\
\hline & 22 & 4-MePh & 16.0 & 0.7 \\
\hline & 23 & $2-\mathrm{Me}, 3,4-\mathrm{OMe}_{2} \mathrm{Ph}$ & Nil & - \\
\hline \multirow{10}{*}{$\stackrel{1}{\mathscr{N}}$} & 24 & Pyridin-2-yl & 13.0 & 0.7 \\
\hline & 25 & Pyridin-3-yl & 10.5 & 0.8 \\
\hline & 26 & Pyridin-4-yl & Nil & - \\
\hline & 27 & Pyrrol-2-yl & 10.5 & 1.0 \\
\hline & 28 & Furan-2-yl & Nil & - \\
\hline & 29 & Indol-3-yl & Nil & - \\
\hline & 30 & Thien-2-yl & 17.0 & 0.6 \\
\hline & 31 & Thien-2-yl-5-Me & 15.0 & 0.7 \\
\hline & 32 & Thien-2-yl-5-Br & 15.5 & 0.6 \\
\hline & 33 & Thien-2-yl-5-NO & 13.5 & 0.7 \\
\hline Standard & & Cefixime & 13.0 & - \\
\hline
\end{tabular}


The lead structure of the library was found to be the 3-bromochalcone (16) with zone of inhibition $18.5 \mathrm{~mm}$ and MIC $0.2 \mathrm{mg} \mathrm{ml}^{-1}$.

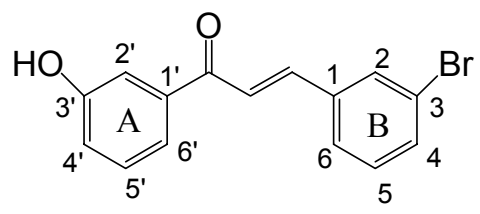

(16)

The most active chalcones e.g. 3-bromo and 3-chloro- have been found to possess high values of hydrophobicity constant $(\pi)$, octanol-water partition coefficient $(\log P$ ) and molar volume $(\mathrm{Vm})$ with the exception of methoxy substituted chalcones. Moreover, the manifested bactericidal effect was also found to be facilitated by the presence of electron acceptors on the phenyl ring of chalcones of Set 1 , the only exception being the nitro group which irrespective of its position on the phenyl ring suppressed the activity of all three regioisomeric chalcones (1820). It may therefore be implied that the lipophilicity of the compounds appeared to be the main predictor of bactericidal activity.

Regarding the potency of chalcones of Set 2, it may be generalized that all chalcones having an azaheterocyclic ring (24-27 \& 29) were found to be either weakly active or inactive. However, thiophene substituted chalcones showed strong bactericidal potential except nitrosubstituted chalcone (33). This characteristic manifested in the thiophene series confirmed our earlier hypothesis that the nitro group attenuates the bactericidal effect. This exceptional behavior of nitrochalcones is in line with our previous study on the effect of substituents on experimentally observed redox potential of a number of substituted chalcones. ${ }^{28)}$

\section{Establishing quantitative structure activity relationship}

For the comprehension of three-dimensional microscopic interactions and binding between a ligand and a receptor, a detail analysis in SAR is important in drug design and synthesis. A number of chemical parameters are reported to be responsible for their molecular interactions. Although many reports on the structure activity relationships based on the biological properties of chalcones have been the subject of a large number of investigations, ${ }^{29-31}$ but the present study is the first report of its nature on the antibacterial activity of chalcones against B. bronchiseptica. The results of in vitro antibacterial activity of chalcones against $B$. bronchiseptica are shown in Table 1. The following two types of molecular descriptors were calculated by software package namely Molecular Operating Environment (MOE), Chemical Computing Group, (Montreal, Canada) in order to derive a quantitative relation between bactericidal activity and structural properties

The values of the calculated electronic parameters are presented in Table 2 while the steric parameters are given in Table 3. These results suggested that not all the parameters were 
essential for bactericidal efficiency e.g. total energy and heat of formation where no regular trend in the variation of activity with these parameters was observed.

The plots of the electronic descriptors as independent variables against zone of inhibition (ZI) values as dependent variable are shown in Figures 2 and 3. A common observation related to all electronic descriptors was that all ortho- and para substituted chalcones as well as heteroarylchalcones were found to fit in the regression line while all the meta substituted chalcones (with the exception of halogenated chalcones) and all nitrochalcones showed deviation when an attempt was made for the correlation of these parameters with the activity.

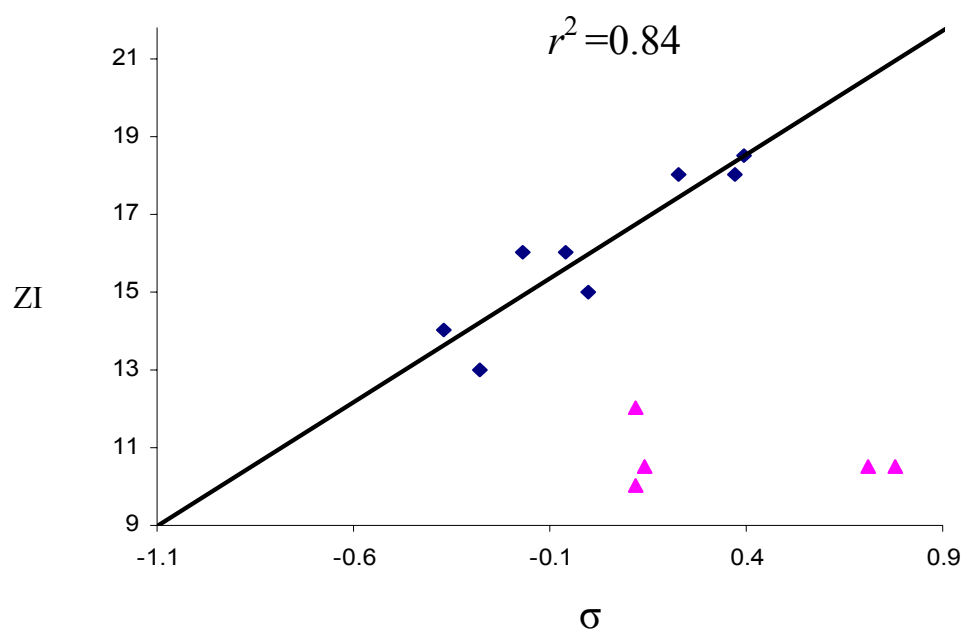

Figure 2. Plot of antibacterial activity (ZI) vs Hammett substituent constant ( $\sigma$ ).

The most important electronic parameters were the Hammett substituent constant $(\sigma)$ and the energy of the frontier orbitals i.e. $E_{\mathrm{HOMO}}$ and $E_{\mathrm{LUMO}}$.

A correlation of the activity with Hammett substituent constant $(\sigma)$ showed that all halogenand para-substituted chalcones of Set 1 bearing substituents e.g. H, 4-OH, 4-OMe, 4-F, 3-Cl, 4$\mathrm{Cl}, 3-\mathrm{Br}$ and 4-Me showed a linear correlation with bactericidal potency and fit in the regression line with value of $r^{2}=0.84$ (Figure 2), the only exception being the $\mathrm{NO}_{2}$ chalcones (18-20). This suppression of the activity by nitro group is also manifested in the series of thiophenesubstituted chalcones where the nitrochalcone (33) was found to be the least potent. This unusual behavior of nitrochalcones as mentioned earlier is in line with our previous observations.

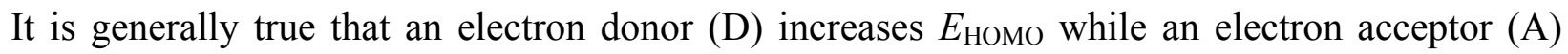
decreases it, therefore, chalcones substituted with D have a higher $E_{\text {Номо }}$ (e.g. OMe and Me substituted chalcones 5-7 and 22) as shown in Table. 2. Since both $E_{\mathrm{HOMO}}$ and $E_{\mathrm{LUMO}}$ represent the electronic interactions, a good inverse relation of the activity with these two parameters was observed $\left(r^{2}=0.83\right)$. Hence an increase in $E_{\text {НОмО }}$ with attenuation in activity was very clearly observed in the following order as shown in Figure 3.

$$
\mathrm{X}>\mathrm{H}>\mathrm{Me}>\mathrm{OH}>\mathrm{OMe}
$$


Table 2. Data set of selected electronic descriptors

\begin{tabular}{|c|c|c|c|c|c|c|c|c|}
\hline \multicolumn{2}{|c|}{ No. } & $\mathrm{R}$ & $\sigma$ & $\begin{array}{c}\mu \\
\text { (Debye) }\end{array}$ & $\begin{array}{c}E_{\text {НОмо }} \\
\left(\text { Kcal.mol }^{-1}\right)\end{array}$ & $\begin{array}{c}E_{\text {LUMO }} \\
\left(\text { Kcal.mol }^{-1}\right)\end{array}$ & $\begin{array}{c}E_{\text {Total }} \\
\left(\text { Kcal.mol }^{-1}\right)\end{array}$ & $\begin{array}{c}\mathrm{ZI} \\
(\mathrm{mm})\end{array}$ \\
\hline \multirow{23}{*}{ 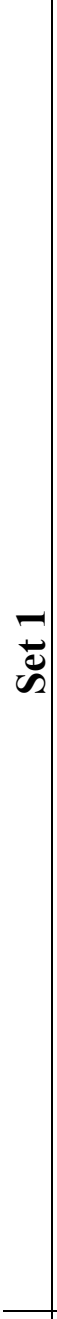 } & 1 & $\mathrm{Ph}$ & 0 & 2.97 & -9.2919 & -0.7252 & 15.14 & 15.0 \\
\hline & 2 & 2-OHPh & - & 4.32 & -9.0542 & -0.6691 & 16.62 & 15.0 \\
\hline & 3 & 3-OHPh & 0.12 & 4.67 & -9.2494 & -0.7526 & 16.21 & 12.0 \\
\hline & 4 & 4-OHPh & -0.37 & 4.53 & -8.9798 & -0.7393 & 16.21 & 14.0 \\
\hline & 5 & 2-OMePh & - & 3.82 & -8.9571 & -0.6005 & 20.06 & 13.0 \\
\hline & 6 & 3-OMePh & 0.12 & 4.61 & -9.1655 & -0.7064 & 18.92 & 10.0 \\
\hline & 7 & 4-OMePh & -0.28 & 4.72 & -8.8963 & -0.6486 & 18.86 & 13.0 \\
\hline & 8 & $3,4-\mathrm{OMe}_{2} \mathrm{Ph}$ & - & 5.76 & -8.7853 & -0.6693 & 39.21 & 11.0 \\
\hline & 9 & 3-OH,4-OMePh & - & 4.74 & - & - & 19.88 & Nil \\
\hline & 10 & 2-FPh & - & 4.88 & -9.3215 & -0.8523 & 12.30 & - \\
\hline & 11 & $3-\mathrm{FPh}$ & 0.34 & 4.4 & -9.3661 & -0.8999 & 12.17 & - \\
\hline & 12 & 4-FPh & -0.06 & 3.02 & -9.2987 & -0.9032 & 15.0 & 16.0 \\
\hline & 13 & 2-ClPh & - & 3.68 & -9.3311 & -0.8226 & 17.34 & 16.0 \\
\hline & 14 & 3-ClPh & 0.37 & 4.21 & -9.3612 & -0.8567 & 15.35 & 18.0 \\
\hline & 15 & 4-ClPh & 0.23 & 3.01 & -9.3193 & -0.9095 & 15.59 & 18.0 \\
\hline & 16 & $3-\mathrm{BrPh}$ & 0.393 & 4.24 & -9.3623 & -0.8729 & 15.46 & 18.5 \\
\hline & 17 & 4-BrPh & 0.23 & 3.03 & -9.3671 & -0.9394 & 12.64 & - \\
\hline & 18 & $2-\mathrm{NO}_{2} \mathrm{Ph}$ & - & 16.34 & 0.9878 & 5.5341 & 21.77 & 11.0 \\
\hline & 19 & $3-\mathrm{NO}_{2} \mathrm{Ph}$ & 0.71 & 12.11 & 1.3693 & 5.679 & 18.96 & 10.5 \\
\hline & 20 & $4-\mathrm{NO}_{2} \mathrm{Ph}$ & 0.78 & 17.75 & 0.6275 & 5.2534 & 18.87 & 10.5 \\
\hline & 21 & $4-\mathrm{NMe}_{2} \mathrm{Ph}$ & -0.6 & 2.87 & - & - & 25.50 & Nil \\
\hline & 22 & 4-MePh & -0.17 & 3.73 & -9.1149 & -0.6761 & 14.86 & 16.0 \\
\hline & 23 & $2-\mathrm{Me}, 3,4-\mathrm{OMe}_{2} \mathrm{Ph}$ & - & - & - & - & & - \\
\hline \multirow{10}{*}{ 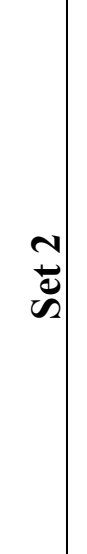 } & 24 & Pyridin-2-yl & - & 5.28 & -9.3486 & -0.8094 & 19.90 & 13.0 \\
\hline & 25 & Pyridin-3-yl & 0.14 & 4.75 & -9.3775 & -0.9422 & 18.71 & 10.5 \\
\hline & 26 & Pyridin-4-yl & 0.13 & 3.06 & -9.4037 & -0.934 & 18.61 & - \\
\hline & 27 & Pyrrol-2-yl & - & 2.41 & -8.5859 & -0.5295 & 23.87 & 10.5 \\
\hline & 28 & Furan-2-yl & - & 4.1 & -9.0909 & -0.795 & 21.76 & - \\
\hline & 29 & Indol-3-yl & - & 3.56 & - & - & 20.87 & - \\
\hline & 30 & Thien-2-yl & - & 3.32 & -9.1719 & -0.8653 & 26.77 & 17.0 \\
\hline & 31 & Thien-2-yl-5-Me & - & 3.51 & -8.9955 & -0.8486 & 26.37 & 15.0 \\
\hline & 32 & Thien-2-yl-5-Br & - & 3.01 & -9.2517 & -1.1269 & 26.20 & 15.5 \\
\hline & 33 & Thien-2-yl-5- $\mathrm{NO}_{2}$ & - & 58.1 & -1.9799 & 3.27 & 34.68 & 13.5 \\
\hline
\end{tabular}


Table 3. Data set of selected steric descriptors

\begin{tabular}{|c|c|c|c|c|c|c|c|c|}
\hline & No. & $\mathrm{R}$ & $\pi$ & $\log P$ & $\begin{array}{c}V m \\
\left(\mathrm{~cm}^{3} \cdot \mathrm{mol}^{-1}\right)\end{array}$ & $\mathrm{M}_{\mathrm{R}}$ & $\begin{array}{c}\mathrm{H}_{\mathrm{f}} \\
\left({\left.\mathrm{Kcal} . \mathrm{mol}^{-1}\right)}^{-1}\right.\end{array}$ & $\begin{array}{r}\mathrm{ZI} \\
(\mathrm{mm})\end{array}$ \\
\hline \multirow{23}{*}{$\overrightarrow{\bar{D}}$} & 1 & $\mathrm{Ph}$ & 0 & 3.79 & 201.37 & -1.8868 & -10.2072 & 15.0 \\
\hline & 2 & 2-OHPh & -0.67 & 3.48 & 199.57 & -1.8935 & -53.6254 & 15.0 \\
\hline & 3 & 3-OHPh & -0.67 & 3.52 & 198.88 & -1.8919 & -53.6308 & 12.0 \\
\hline & 4 & 4-OHPh & -0.67 & 3.48 & 198.88 & -1.8914 & -37.4067 & 14.0 \\
\hline & 5 & 2-OMePh & -0.02 & 3.74 & 219.94 & -1.9737 & -46.906 & 13.0 \\
\hline & 6 & 3-OMePh & -0.02 & 3.78 & 219.86 & -1.9693 & -47.4043 & 10.0 \\
\hline & 7 & 4-OMePh & -0.02 & 3.75 & 219.84 & -1.9682 & -38.6567 & 13.0 \\
\hline & 8 & $3,4-\mathrm{OMe}_{2} \mathrm{Ph}$ & - & 3.49 & 238.28 & -2.0113 & -75.8321 & 11.0 \\
\hline & 9 & 3-OH,4-OMePh & - & 2.13 & 217.39 & - & - & Nil \\
\hline & 10 & 2-FPh & 0.14 & 3.95 & 212.02 & -1.8846 & -53.8489 & - \\
\hline & 11 & $3-\mathrm{FPh}$ & 0.14 & 3.98 & 212.02 & -1.8851 & -54.6461 & - \\
\hline & 12 & 4-FPh & 0.14 & 3.94 & 212.99 & -1.8853 & -55.3716 & 16.0 \\
\hline & 13 & 2-ClPh & 0.71 & 4.38 & 214.08 & -1.8817 & -15.5506 & 16.0 \\
\hline & 14 & 3-ClPh & 0.71 & 4.42 & 213.95 & -1.883 & -16.7515 & 18.0 \\
\hline & 15 & 4-ClPh & 0.71 & 4.38 & 213.93 & -1.8834 & -16.8489 & 18.0 \\
\hline & 16 & 3-BrPh & 0.86 & 4.62 & 216.33 & -1.8822 & -4.6122 & 18.5 \\
\hline & 17 & 4-BrPh & 0.86 & 4.59 & 216.32 & -1.8827 & -4.5937 & - \\
\hline & 18 & $2-\mathrm{NO}_{2} \mathrm{Ph}$ & -0.28 & 3.32 & 191.72 & -1.9001 & -8.469 & 11.0 \\
\hline & 19 & $3-\mathrm{NO}_{2} \mathrm{Ph}$ & -0.28 & 3.36 & 190.65 & -1.8971 & -0.7997 & 10.5 \\
\hline & 20 & $4-\mathrm{NO}_{2} \mathrm{Ph}$ & -0.28 & 3.32 & 190.69 & -1.8962 & -25.0921 & 10.5 \\
\hline & 21 & $4-\mathrm{NMe}_{2} \mathrm{Ph}$ & 0.18 & 2.41 & 237.37 & - & - & Nil \\
\hline & 22 & 4-MePh & 0.56 & 4.09 & 217.64 & -1.9897 & -16.825 & 16.0 \\
\hline & 23 & $2-\mathrm{Me}, 3,4-\mathrm{OMe}_{2} \mathrm{Ph}$ & - & - & - & - & - & Nil \\
\hline \multirow{10}{*}{$\stackrel{N}{\stackrel{N}{D}}$} & 24 & Pyridin-2-yl & - & 2.52 & 206.03 & -1.8777 & 2.8487 & 13.0 \\
\hline & 25 & Pyridin-3-yl & - & 2.56 & 206.08 & -1.8799 & -0.2678 & 10.5 \\
\hline & 26 & Pyridin-4-yl & - & 2.56 & 206.07 & -1.8806 & 3.5512 & - \\
\hline & 27 & Pyrrol-2-yl & - & 2.52 & 167.07 & -1.8732 & 5.8471 & 10.5 \\
\hline & 28 & Furan-2-yl & - & 2.51 & 169.30 & -1.8716 & -28.0442 & Nil \\
\hline & 29 & Indol-3-yl & - & 1.60 & 211.86 & - & - & Nil \\
\hline & 30 & Thien-2-yl & - & 3.32 & 189.87 & -1.8707 & -5.5895 & 17.0 \\
\hline & 31 & Thien-2-yl-5-Me & - & 3.50 & 206.09 & -1.907 & -13.0335 & 15.0 \\
\hline & 32 & Thien-2-yl-5-Br & - & 4.33 & 204.64 & -1.8707 & -2.6183 & 15.5 \\
\hline & 33 & Thien-2-yl-5- $\mathrm{NO}_{2}$ & - & 3.07 & 180.21 & -1.8707 & -41.1641 & 13.5 \\
\hline
\end{tabular}




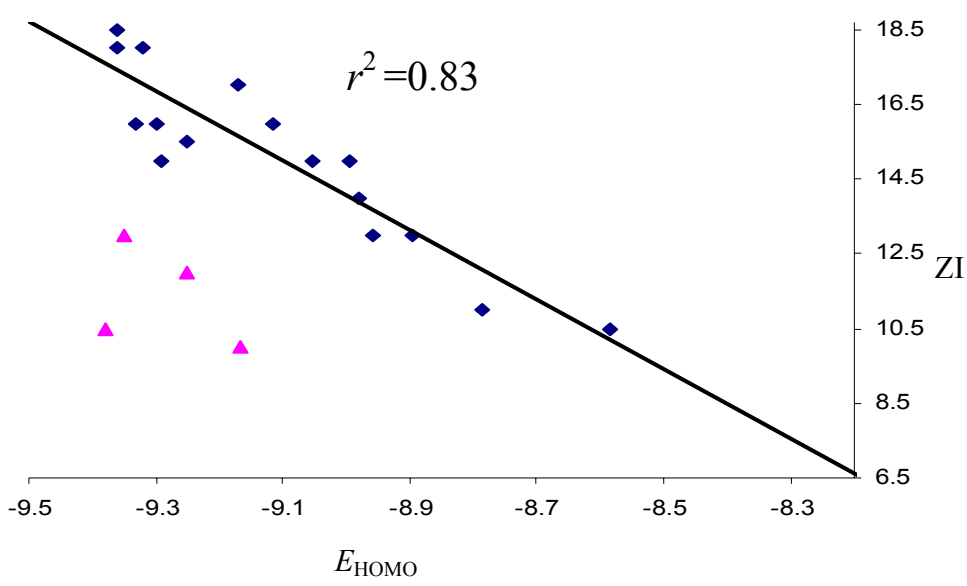

Figure 3. Plot of antibacterial activity (ZI) vs $E_{\mathrm{HOMO}}$

Regarding a correlation of the steric parameters with activity, all chalcones of both sets were found to correlate directly with the activity with the exception of methoxy and pyridylchalcones. The octanol-water partition coefficient $(\log P)$ is representative of steric interactions and in the present study it showed a good correlation with the bactericidal action of chalcones of both sets except 3-OMe and 2- pyridylchalcones. A direct correlation of the activity with $\log P\left(r^{2}=0.82\right)$ was indicative of the fact that chalcones with a higher $\log P$ are expected to be more active as is reflected in the activity of the series of halogenated chalcones (Figure 4).

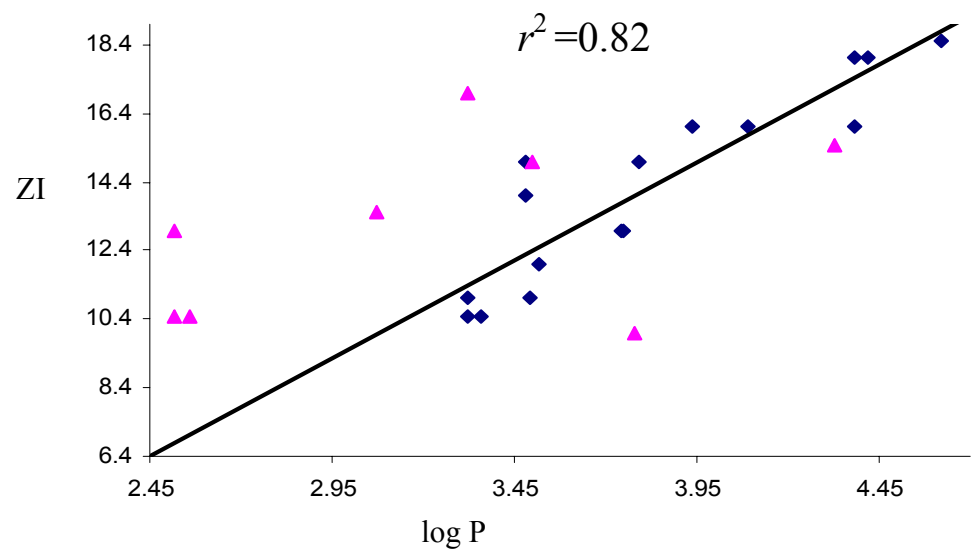

Figure 4. Plot of antibacterial activity (ZI) vs octanol-water partition coefficient $(\log P)$. 
A direct correlation of the antibacterial potential of chalcones of both sets with another steric parameter i.e. $\operatorname{Vm}\left(r^{2}=0.88\right)$ was observed. As it is evident from Figure 5 , the activity of chalcones increases with an increase in the molar volume and the following order of potency of the bactericidal action was observed

$$
\mathrm{Br}>\mathrm{Cl}>\mathrm{F}>\mathrm{H}>\mathrm{OH} \text {. }
$$

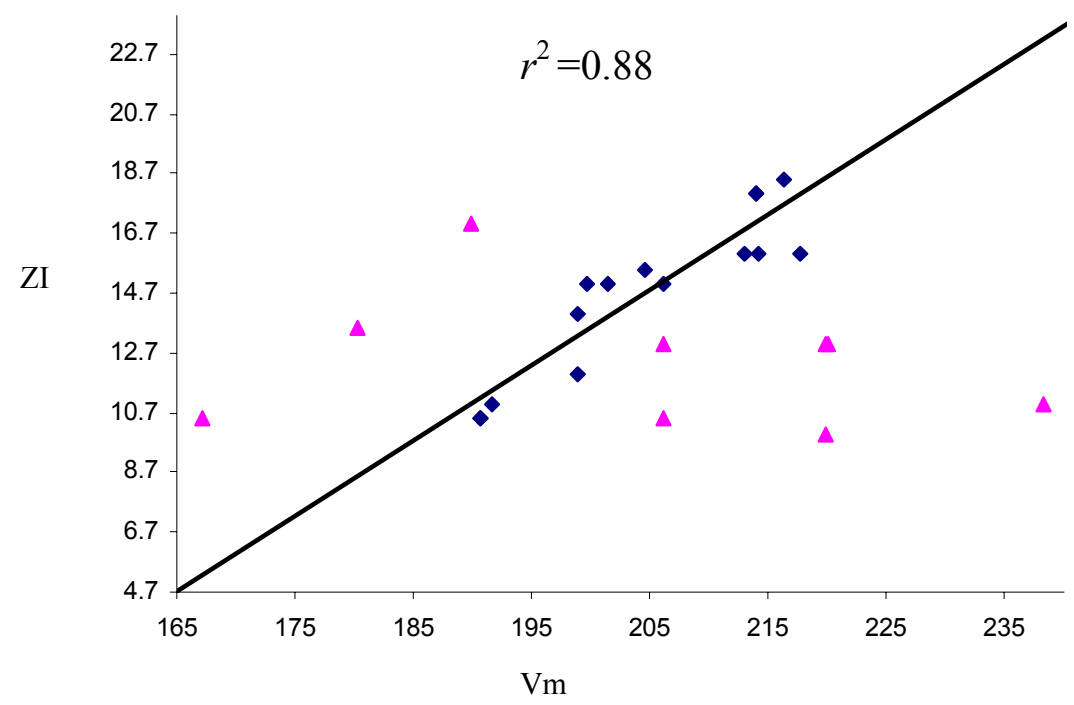

Figure 5. Plot of antibacterial activity $(\mathrm{ZI})$ vs molar volume $(\mathrm{Vm})$

\section{Conclusions}

An echo-friendly synthesis of a 33-membered library of 3-hydroxychalcones has been conducted under microwave irradiation. These chalcones were found to be active against $B$. bronchiseptica which is a gram positive bacterium responsible for respiratory tract infections both in animals and humans. Agar well diffusion method was employed for antibacterial testing using cefixime as standard drugs. The halogen substituted chalcones were found to be the most active members of the library, the nitrochalcones least active whereas hydroxy and methoxy substituted chalcones were intermediate in activity. Two types of molecular descriptors i.e. electronic and steric were calculated by software package MOE in order to derive a quantitative relation between bactericidal activity and structural properties. A direct structure activity correlation was observed in case of steric parameters and the most active chalcones (14 and 16) were found to possess high values of $\pi, \log P$ and $V m$. It may therefore be generalized that the lipophilicity of the compounds appears to be the main predictor of bactericidal activity against $B$. bronchiseptica. However, of the electronic parameters, an inverse relation between $E_{\mathrm{HOMO}}$ and bactericidal potential was observed and the chalcones substituted with electron acceptors with a low lying HOMO were found to be the more active members of the library. It is therefore 
suggested that the chalcones with electron acceptors on ring B (with the exception of nitrochalcones) having a greater lipophilic character are expected to be strong inhibitors of $B$. bronchiseptica.

\section{Experimental Section}

General Procedures. Melting points were determined in open capillaries on a Mel-Temp apparatus and are uncorrected. Domestic purpose microwave oven (LG, Model: MS-304A, Microwave:1250W, RF output: $900 \mathrm{~W}$ and $2450 \mathrm{Mz}$ ) was used for synthesis. IR spectra were recorded on a Schimadzu FTIR-270 spectrophotometer $\left(\mathrm{KBr}, 400-4000 \mathrm{~cm}^{-1}\right) .{ }^{1} \mathrm{H}-\mathrm{NMR}$ spectra were recorded on a Bruker NMR spectrometer at $300 \mathrm{MHz}$ using tetramethylsilane as an internal reference. Chemical shifts are given in parts per million (ppm). Thin-layer chromatography was performed on Merck silica gel $F_{254}$ plates $(0.25 \mathrm{~mm})$. Some of the compounds synthesized were purified through flash chromatography using silica gel; Keisel gel G-60 (Fluka). All solvents and reagents were obtained either from Fluka or Aldrich and were used without further purification. The synthesis of chalcones 1-33 was carried out by the reaction of 3-hydroxyacetophenone with a number of substituted aryl and heteroaryl aldehydes via Claisen Schmidt condensation under microwave irradiation leading to two sets of chalcones; Set 1 comprising of chalcones 1-23 while Set 2 comprised of chalcones 24-33. The reaction time varied from 30-180 sec while the yield varied from 51-93\%. The chalcones 2, 3, 4, 6, 22, 26, 28, 29 and 33 were obtained in relatively low yield.

\section{Conventional synthesis of chalcones}

Chalcone 2-4, 9 and heteroaryl chalcones (24-33) were synthesized by conventional method as reported earlier. ${ }^{18}$

\section{Microwave assisted synthesis of chalcones}

Chalcone 1, 5-8 and 10-23 were synthesized using microwave oven. To a solution of methylketone $(0.01$ mole) and aromatic aldehyde $(0.01$ mole or 0.02 moles $)$ in dry ethanol (20 $\mathrm{ml})$ taken in a beaker $(100 \mathrm{ml})$, a catalytic quantity of sodium hydroxide (1-2 pellets) was added and the reaction mixture was heated inside a microwave oven for $30 \mathrm{sec}$ to $180 \mathrm{sec}$. (at 210 Watts, i.e. 30\% microwave power). The reactions were monitored through TLC using solvent system (a) ethyl acetate : n-hexane (1:2), (b) ethyl acetate : n-hexane (1:3) and (c) acetone : nhexane (1:3). When the reaction was found to be complete, then reaction mixture was cooled in an ice bath and the product thus formed was filtered, washed with ethanol followed by washing with water till the washings were neutral and recrystallized by distilled ethanol. Some of the compounds 24-33 were purified through flash chromatography using silica gel Keisel gel G-60 (Fluka) ethyl acetate- n-hexane (4:1) as eluent. 


\section{Determination of antibacterial activity}

All compounds were tested against six bacterial strains B. bronchiseptica, M. leuteus, $P$. picketti, E. coli, E. aerogenes and S. Setubal. The agar well-diffusion method was applied for the determination of inhibition zone and minimum inhibitory concentration (MIC). Briefly, $0.75 \mathrm{ml}$ of broth culture containing $c a .10^{6}$ colon-forming units (CFU) per $\mathrm{ml}$ of the test strain was added to $75 \mathrm{ml}$ of nutrient agar medium at $45^{\circ} \mathrm{C}$, mixed well, and then poured into a $14 \mathrm{~cm}$ sterile metallic Petri plate. The medium was allowed to solidify, and $8 \mathrm{~mm}$ wells were dug with a sterile metallic borer. Then, a DMSO solution of the test sample $(100 \mu \mathrm{l})$ at $1 \mathrm{mg} / \mathrm{ml}$ was added to the respective wells. DMSO served as negative control, and the standard antibacterial drug Cefixime $^{\circledR}(1 \mathrm{mg} / \mathrm{ml})$ were used as positive controls. Triplicate plates of each bacterial strain were prepared and were incubated aerobically at $37{ }^{\circ} \mathrm{C}$ for $24 \mathrm{~h}$. The activity was determined by measuring the diameter of zone showing complete inhibition $(\mathrm{mm})$, thereby, the zones were precisely measured with the aid of a Vernier Caliper (precision $\pm 0.1 \mathrm{~mm}$ ). The growth inhibition was calculated with reference to the positive control.

\section{Determination of minimum inhibitory concentrations}

For the individual chalcones that showed inhibition zones $>10 \mathrm{~mm}$, MIC values were determined by means of the agar well-diffusion method for concentrations of 1.0, 0.8, 0.6, 0.4, $0.3,0.2$ and $0.1 \mathrm{mg} / \mathrm{ml}$ in DMSO. The tests were performed in triplicate, and the results were averaged.

\section{Computer modeling and calculation of the electronic and steric descriptors}

The software package MOE (Molecular Operating Environment) was used to generate the descriptor-based QSAR. The final structures that represented the most stable conformer for a given compound were used to obtain these descriptors. The following descriptors were selected and calculated as they represented electronic and steric features of the compounds studied and are known to be important for biological activity.

Electronic descriptors:

- Hammett substituent constant $(\sigma)$

- Dipole moment $(\mu)$

- $\quad$ Energy of frontier orbitals $\left(E_{\mathrm{HOMO}} \& E_{\mathrm{LUMO}}\right)$

- Total energy of the most stable conformer $\left(E_{\text {Total }}\right)$

Steric descriptors:

- Octanol-water partition coefficient $(\log P)$

- Substituent's hydrophobicity constant $(\pi)$

- Molecular volume $(\mathrm{Vm})$

- Molecular refractivity $\left(\mathrm{M}_{\mathrm{R}}\right)$

- Heat of formation $\left(\mathrm{H}_{\mathrm{f}}\right)$

A first order polynomial relationship was obtained with a number of both electronic and steric parameters. In some cases unsatisfactory correlation was obtained, but after omitting some 
chalcones linear and better relationship was obtained with significantly higher correlation coefficients. These relations have suggested that the compounds with maximal inhibition should possess a $\log P$ value at least 3.5.

\section{Acknowledgements}

The authors are grateful to the Higher Education Commission, Pakistan for financial support.

\section{References}

1. Rougier, S.; Galland, D.; Boucher, S.; Boussarie, D.; Vallé, M. Veter. Microbio. 2006, 115, 192.

2. Lorenzo-Pajuelo, B.; Villanueva, J. L.; Rodriguez-Cuesta, J.; Vergara-Irigary, N.; BernabeuWittel, M.; Garcia-Curiel, A.; Martinez de Tejada, G. J. Clin. Microbio. 2002, 40, 3146.

3. Gueirard, P.; Bassinet, L.; Bonne, I.; Prevost, M. C.; Guiso, N. Microbio. Pathog. 2005, 38, 41.

4. Stevenson, A.; Roberts, M. Vaccine 2002, 20, 2325.

5. Shin, S. J.; Kang, S.G.; Nabin, R.; Kang, M. L.; Yoo, H. S. Veter. Microbio. 2005, 106, 73.

6. Nowakowska, Z. Eur. J. Med. Chem. 2007, 42, 125.

7. Gacche, R. N.; Dhole, N. A.; Kamble, S. G.; Bandgar, B. P. J. Enzym. Inhib. Med. Chem. 2008, 23, 28.

8. Deng, J.; Sanchez, T.; Al-Mawsawi, L. Q.; Dayam, R.; Yunes, R. A.; Garofalo, A.; Bolger, M. B.; Neamati, N. Bioorg. Med. Chem. 2007, 15, 4985.

9. Sivakumar, P. M.; Seenivasan, S. P.; Kumar, V.; Doble, M. Bioorg. Med. Chem. Lett. 2007, $17,1695$.

10. Kraus, G. A.; Kumar, G.; Phillips, G.; Michalson, K.; Mangano, M. Bioorg. Med. Chem. Lett. 2008, 18, 2329.

11. Nielsen, S. F.; Christensen, S. B.; Cruciani, G.; Kharazmi, A.; Liljefors, T. J. Med. Chem. 1998, 41, 4819.

12. Yarishkin, O. V.; Ryu, H. W.; Park, J.; Yang, M. S.; Hong, S.; Park, K. H. Bioorg. Med. Chem. Lett. 2008, 18, 137.

13. Sivakumar, P. M.; Geetha, S. K. B.; Mukesh, D. Chem. Pharm. Bull. (Tokyo) 2007, 55, 44.

14. Pilone, M. R.; Harvill, E. T. Infec. Immun. 2006, 74, 1043.

15. Nowakowska, Z.; Kedzia, B.; Schroeder, G. Eur. J. Med. Chem. 2008, 43, 707.

16. Nielsen, S. F.; Boesen, T.; Larsen, M.; Schønning, K.; Kromann, H. Bioorg. Med. Chem. 2004, 12, 3047.

17. Sharma, P.; Sharma, S.; Rane, N. Bioorg. Med. Chem. 2004, 12, 3135. 
18. Ansari, F. L.; Nazir, S.; Noureen, H.; Mirza, B. Chem. Biodiv. 2005, 2, 1656.

19. Ansari, F. L.; Umbreen, S.; Hussain, L.; Makhmoor, T.; Nawaz, S. A.; Lodhi, M. A.; Khan, S. N.; Shaheen, F.; Choudhary, M. I.; Atta-Ur-Rahman Chem. Biodiv. 2005, 2, 487.

20. Ullah, A.; Ansari, F. L.; Haq, I. U.; Nazir, S.; Mirza, B. Chem. Biodiv. 2007, 4, 203.

21. Narender, T.; Reddy, K. P. Tetrahedr. Lett. 2007, 48, 3177.

22. Go, M. L.; Wu, X.; Liu, X. L. Curr. Med. Chem. 2005, 12, 483.

23. Cabrera, M.; Simoens, M.; Falchi, G.; Lavaggi, M. L.; Piro, O. E.; Castellano, E.; Vidal, A.; Azqueta, A.; Monge, A.; Deceráin, A. L.; Sagrera, G.; Seoane, G.; Cerertto, H.; Gonzalez, M. Bioorg. Med. Chem. 2007, 15, 3356.

24. Calvino, V.; Picallo, M.; Lopez-Peinado, A. J.; Martín-Aranda, R. M.; Durán-Valle, C. J. Appl. Surf. Sci. 2006, 252, 6071.

25. Perozo-Randón, E.; Martin-Aranda, R. M.; Casal, B.; Durán-Valle, C. J.; Lau, W. N.; Zhang, F.; Yeung, K. L. Catal. Today 2006, 114, 183.

26. Dandia, A.; Singh, R.; Khaturia, S. Bioorg. Med. Chem. 2006, 14, 1303.

27. Molecular Operating Environment (MOE), Chemical Computing Group, Montreal, Canada, 2007.

28. Rahman, A.; Qureshi, R.; Kiran, M.; Ansari, F. L. Turk. J. Chem. 2006, 30, 1.

29. Xue, C. X.; Cui, S. Y.; Liu, M. C.; Hu, Z. D.; Fan, B. T. Eur. J. Med. Chem. 2004, 39, 745.

30. Xu, Y. C.; Leung, S. W. S.; Yeung, D. K. Y.; Hu, L.H.; Chen, G. H.; Che, C. M.; Man, R. Y. K. Phytochem. 2007, 68, 1179.

31. Gacche, R.; Khsirsagar, M.; Kamble, S.; Bandgar, B.; Dhole, N.; Shisode, K.; Chaudhari, A. Chem. Pharm. Bull. 2008, 56, 897. 